\title{
Holiploigy - navigating the complexity of teaching in higher education
}

\section{Phil Wood}

School of Education, University of Leicester, UK

\section{Abstract}

The processes involved in teaching in higher education, as with schools, have on occasion become simplified to a dichotomy of being either 'transmission' or 'discovery' led. Such characterisations of teaching fail to engage with the context driven complexities of teaching, learning, curriculum and assessment. This opinion piece reflects upon the complexities involved and how they might be characterised and explained without reducing teaching and allied processes to simplistic frameworks. I argue that we need to develop holistic, process-led models of teaching, learning, curriculum and assessment, and associated systems for module and programme development and execution, a combined set of processes and principles that I refer to here as holiploigy.

Keywords: complexity; teaching; holiploigy; process; educational experiences.

\section{Introduction}

Historically, the role of teaching in universities was to provide academics with an income on which they could rely whilst immersed in their research. Vestiges of this mindset remain in many universities, where research is considered a 'high-level' cognitive act, whilst the practice of teaching is deemed to be some form of lesser activity. However, over time there has emerged a developing interest in seeing teaching as an important area of endeavour within the academy. The development of Scholarship of Teaching and Learning (Boyer, 1990), whilst still contested in terms of focus and detail, has begun to highlight the multi-faceted nature of teaching. In several countries, frameworks (however imperfect) for officially recognising excellence in teaching have been developed, for example, the conferring of fellow status on individuals by the Higher Education Academy. In England, 
this focus on teaching has now taken another step forward due to the introduction of student fees. With any market in a service comes the inevitable need to differentiate, in this case through the development of the Teaching Excellence Framework (Gunn, 2015). Because of these changes, increasing interest in teaching is being taken by university leadership teams keen to demonstrate that they are listening to students and providing them with a high-quality experience commensurate with the fees they are paying.

The emerging interest being shown in teaching can seem somewhat performative (Ball, 2012) in nature, focusing on those areas of activity which will have the greatest impact on student evaluations. In some cases, 'corporate narratives' relating to teaching have developed to offer unique selling points in the educational market. It is in this context that roughly two years ago, I started to question what the role of my teaching is in a higher education environment. I predominantly teach international post-graduate students at masters' level on both face-to-face and distance learning courses. Whilst hugely valuing my work and using my teaching as a basis for my research, I felt unsure about how to conceptualise what I am trying to achieve with these students, I have also sensed that organisational narratives are beginning to diverge from the processes and philosophies which underpin my own praxis. What follows is an initial reflection on how I have come to think about teaching at higher education level, and through this I attempt to offer an alternative perspective on how we might understand our work with students, as well as our own emergence as experts in teaching, a perspective I refer to as holiploigy, relating to a network of processes and systems as briefly outlined in the abstract above and expanded on below.

\section{What is a teacher?}

Teaching is not a single universally accepted form of practice (Kreber, 2013); there are many different views of what constitutes the process of teaching and, by extension, teachers. Tubbs (2005) outlines the contrast between teacher as master and teacher as servant, the former being central to the teaching process, 'delivering' content to students and dictating the environment for learning, whilst the latter is more a facilitator, supporting the discovery process driven by students. Whilst these characterisations suggest extreme positions, this debate is an important one as some institutions move towards problem and enquiry-based learning as the only legitimate approach to the educational experience. 
Biesta (2016) makes a sound argument for seeing teaching as being central to the educational experience. In opposition to an 'egological' experience (which can lead to a restricted experience of learning which starts and ends with the individual), teaching can fulfil the role of helping students engage with a wide experience of disciplinary expertise offered by the teacher. Rather than allowing for the opening up to new perspectives through dialogue and alternative perspectives, student-led approaches, if dominant, can lead to a restricted worldview. There is a need to develop a balanced view which sees the teacher as offering both expertise and guidance. The teacher needs to understand the complexity involved in helping students to encounter the world via the act of teaching, fulfilling many possible roles dependent on the context and aims of the educational experience at any point in time; teaching should not be a narrowly defined process.

\section{What are we trying to achieve?}

Is it enough to see the work of teachers as centred on understanding 'teaching' alone? It is all too easy to see teaching as an event-orientated activity. We teach 'lessons', we create a 'curriculum'; these take the form of events and substances, such as handouts, resources on virtual learning environments, PowerPoints. But an alternative perspective is that which comes from process philosophy, 'temporality, activity, and change - of alteration, striving, passage, and novelty-emergence - are the cardinal factors for our understanding of the real' (Rescher, 2000, p.6). Here, it is the flow of processes which is central to understanding reality. Substances and events are important, but so are transient nodes and clusters in the flow of process. But teaching cannot then be a singular thing. It is in constant interaction with learning (both student and teacher), the curriculum and assessment (see Figure 1). Conceptualising the activity of teachers as 'teaching and learning' becomes reductive as the formal activity of university teaching must be understood not only in relation to learning, but also curriculum and assessment. 
Figure 1. See teaching as part of a wider complex of processes.

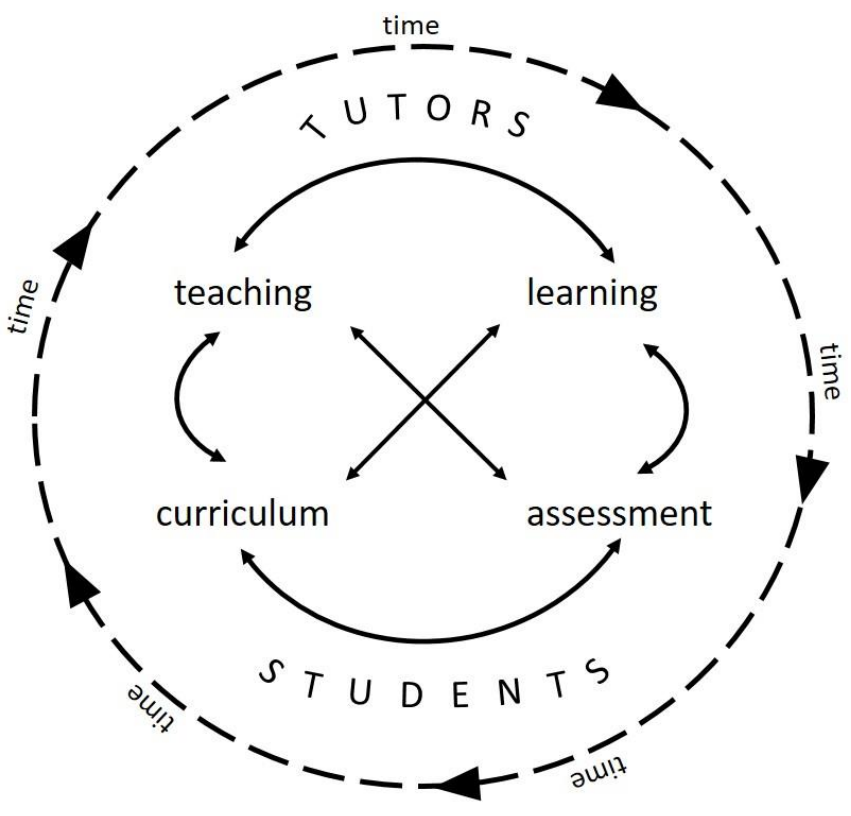

But these four interpenetrating systems cannot themselves be an exhaustive account of the teaching process, as they are meaningless without the presence of tutor and students. It is the interaction of humans with teaching, learning, curriculum and learning which creates educative experiences and change. Finally, change emerges over time: experience and learning are temporally driven processes.

This account of the elements of educative experience and change is characterised by a series of interpenetrating complex adaptive systems (Byrne and Callaghan, 2014). Much of the higher education literature has ignored the insights offered by complexity theory, but the many processes involved in teaching are non-linear in nature and emergent in form. Rather than seeing teaching as a simple, linear process, if we are to begin to capture the reality of the many processes involved we must recast them as contextualised, emergent and complex. To become expert in developing educational experiences and change, we need to have a far reaching and holistic understanding of this complexity.

\section{Beyond teaching - the complex nature of the educational experience?}

Any attempt to capture the complexity of educational experiences and change in their entirety will fail. This is because they are context driven and will involve almost limitless 
combinations of processes. Different disciplines, under- and post-graduate, face-to-face, blended, or distance learning, will all lead to different practice. What appears below (Figure 2) is an attempt to capture only some of the possible wider elements which might act as important features and processes in the emergence of practice and expertise. Such complexity reduction (Biesta, 2010) is bound to occur as any exhaustive model of a complex system would need to be as complete as the system itself, which is not possible. However:

Just because a complex system is incompressible it does not follow that there are (incomplete) representations of the system that cannot be useful - otherwise how would we have knowledge of anything, however limited? Incompressibility is not an excuse for not bothering.

Richardson and Tait (2010, pp.92-93)

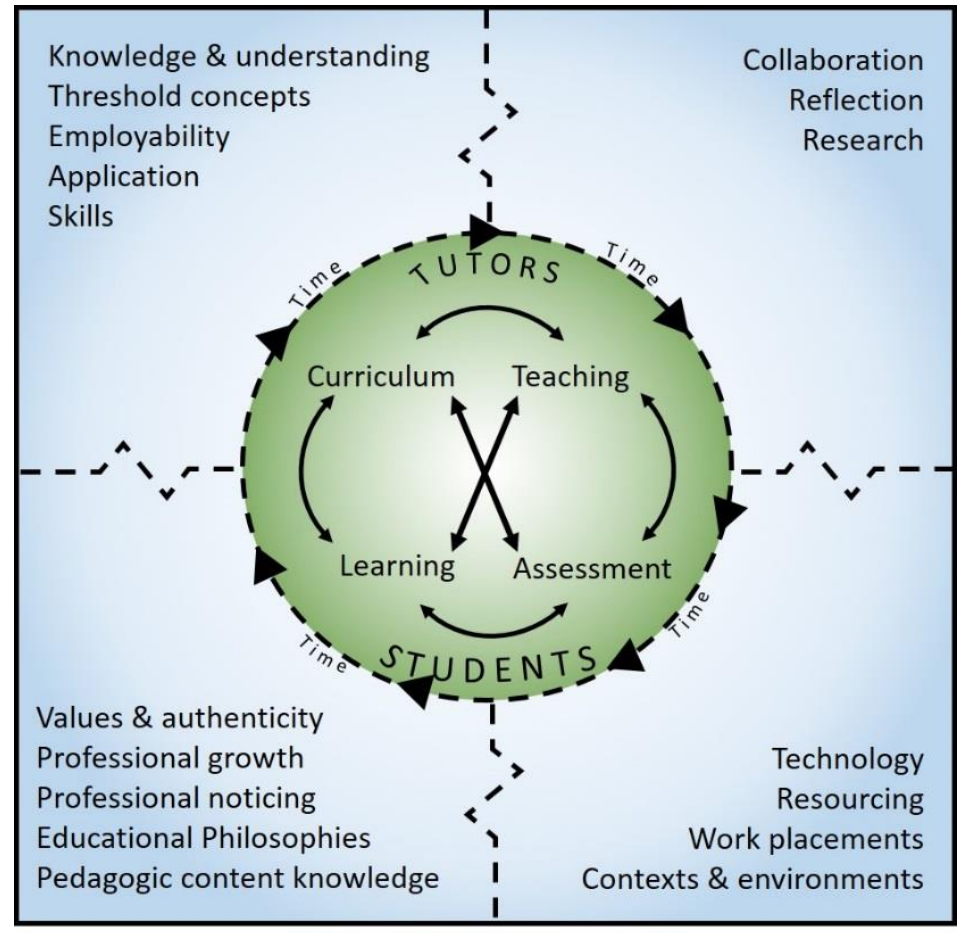

Figure 2. An expanded model of complexity in educational experiences and change.

As well as the elements which appeared in figure 1, there are a series of other processes and issues which are part of this complex system. In this view of the educational experience, teachers learn as much as students, although the professional growth involved is of a different form and focus. Educational values and philosophies are crucial to 
bringing authenticity (Kreber, 2013) to praxis focused on the understanding and practical application of disciplinary concepts, application of knowledge, and links to employability. The environments (both formal and informal) through which the processes emerge need to be considered, leading to the need to understand and apply the contributions offered by technology, resources and possibly work placements, as well as different formal teaching contexts. Finally, to foster emergent expertise, teachers need to reflect upon their philosophies and values and their resultant practices to aid emergence of new perspectives and approaches. This can be done alone but, at least some of the time, it can be aided by communal activity as a way of overcoming 'pedagogic solitude' (Shulman, 1993). Such collaboration can make use of pre-existing research to inform and can also generate research, making praxis central to the work of teachers.

This outline, as stated above, will only ever capture some of the processes and issues pertinent to any given context. It can act as a starting point for discussion and reflection, however, it cannot offer an exhaustive account or 'roadmap' for creating a single 'best' framework or recipe book for practical expertise in teaching. Seen through a complexity lens, it is only possible to offer insight and reflection on experience. What is offered is a philosophy, not a set of rules.

\section{Why holiploigy? Capturing the complexity of teaching in higher education}

The outline given in figure 2 is an attempt to capture, however incompletely, the complexity of the tasks involved in the conduct of higher education. But what might this set of processes be called? Some of my initial interest in this idea came from a linguistic problem - I had no name for the complex set of processes outlined here. 'Pedagogy' seems inappropriate as etymologically it means to 'lead children'. This is a higher education orientated model relating to adults, and I do not see my role as one which only 'leads'. This then also discounts 'andragogy' (Knowles, 1970) as once again, whilst it stresses an interaction with adults, it still suggests a form of leading, albeit linked to self-direction. The only other possible pre-existing term is heutagogy (Hase and Kenyon, 2000). Whilst this stresses the notion of self-determined learning, literally 'self-leading', this potentially 'sidelines' the teacher in the way suggested by Biesta (2016), potentially leading to impoverished 'egological' (that is wanting to move away from a teaching experience which 
is focused only on the student) experiences. Firstly, the task at hand suggests a level of complexity, in terms of how we understand the processes of teaching, learning, curriculum and assessment, as well as their interpenetration to create learning experiences. However, there is also the complexity of the processes which intertwine with this core, the contexts, philosophies, and the emergence of the teacher's own practice. This leads to the need to think holistically on many different levels (holi-).

Thinking back to the work of Tubbs (2005), I also want to consider how we might create an analogy for the role of the teacher. Running through the discussion above is the importance of context, of varied approaches which might be appropriate at different points in the educational experience. At some points the teacher may need to play the role of a leader, introducing content, creating structures to help students understand the 'shape' of an area of a discipline. Given the inclusion of threshold concepts (Meyer and Land, 2003) in the model, there may be times when students struggle with troublesome knowledge (Perkins, 1999), as they traverse liminality. Here, the teacher plays an explicit and leading role. But at other points, and in different contexts, the teacher is more peripheral, at times fulfilling the role as suggested by heutagogy, guiding and offering support when required. I see this ability to gauge, to help students understand the terrain through which they are moving, as a form of navigation ('ploigos' in ancient Greek). Hence, the holistic process of helping others navigate through a disciplinary terrain whilst also developing our own expertise, becomes a process of holiploigy. An initial definition for this concept would read:

Holiploigy is the emergent enactment of the processes of educative experiences. It is based on the complex interaction of curriculum, teaching, learning and assessment as enacted by tutors and students, mediated through philosophies, contexts and research. These emergent processes foster the growth of expertise in both tutors and students.

I suggest that the acceptance of this definition would have several ramifications for the perceived place of teaching in higher education, and for the increasing number of simplistic and reductive frameworks being used to measure its quality. 


\section{References}

Ball, S.J. (2012) 'Performativity, commodification and commitment: an I-spy guide to the neoliberal university', British Journal of Educational Studies, 60(1), pp. 17-28.

Biesta, G.J.J. (2010) 'Five theses on complexity reduction and its politics', in Osberg, D.C. and Biesta, G.J.J. (eds.) Complexity theory and the politics of education. Rotterdam: Sense Publishers, pp. 5-13.

Biesta, G.J.J. (2016) 'The rediscovery of teaching: on robot vacuum cleaners, nonegological education, and the limits of the hermeneutical worldview', Educational Philosophy and Theory, 48(4), pp. 374-392 [Online]. Available at: http://bura.brunel.ac.uk/handle/2438/10587 (Accessed: 3 April 2017).

Boyer, E.L. (1990) Scholarship reconsidered: priorities of the professoriate. Princeton, N.J: Carnegie Foundation for the Advancement of Teaching.

Byrne, D. and Callaghan, G. (2014) Complexity theory and the social sciences: the state of the art. Abingdon: Routledge.

Gunn, A. (2015) 'How the Teaching Excellence Framework will work', The Conversation, 6 November [Online]. Available at: https://theconversation.com/how-the-teachingexcellence-framework-will-work-50323 (Accessed: 27 February, 2017)

Hase, S. and Kenyon, C. (2000) From andragogy to heutagogy. Ultibase, RMIT [Online]. Available at: http://pandora.nla.gov.au/nphwb/20010220130000/http://ultibase.rmit.edu.au/Articles/dec00/hase2.htm (Accessed: 3 April 2017).

Knowles, M.S. (1970) The modern practice of adult education. Andragogy versus pedagogy. Englewood Cliffs: Prentice Hall/Cambridge.

Kreber, C. (2013) Authenticity in and through teaching in higher education: the transformative potential of the scholarship of teaching. Abingdon: Routledge. 
Meyer, J.H.F. and Land, R. (2003) Threshold concepts and troublesome knowledge: linkages to ways of thinking and practising within the disciplines. Enhancing Teaching-Learning Environments in Undergraduate Courses Project, Occasional Report 4, May 2003. Available at: http://www.etl.tla.ed.ac.uk/docs/ETLreport4.pdf (Accessed: 22 October 2016).

Perkins, D. (1999) 'The many faces of constructivism', Educational Leadership, 57(3), pp. 6-11.

Rescher, N. (2000) Process philosophy: a survey of basic issues. Pittsburgh: University of Pittsburgh Press.

Richardson, K.A. and Tait, A. (2010) 'The death of the expert?' E:CO, 12(2), pp. 87-97.

Shulman, L.S. (1993) 'Teaching as community property: putting an end to pedagogical solitude', Change, 25(6), pp. 6-7.

Tubbs, N. (2005) Philosophy of the teacher. Oxford: Blackwell.

\section{Author details}

Phil Wood, Associate Professor in Education. School of Education, University of Leicester, LE1 7RF, pbw2@le.ac.uk, @HEreflections1 